Cita bibliográfica: De Murcia Conesa, A. (2018). Mirar el dispositivo. Variaciones sobre el ojo y la máquina. [Looking at the device.Variations on the eye and the machine]. PHI. Revista internacional de Filosofía Contemporánea y Filosofía de la Imagen, 0, $72-86$.

\title{
MIRAR EL DISPOSITIVO. VARIACIONES SOBRE EL OJO Y LA MÁQUINA
}

\author{
LOOKING AT THE DEVICE. \\ VARIATIONS ON THE EYE AND THE MACHINE
}

\author{
Antonio de Murcia Conesa \\ Universidad de Alicante
}

\section{Resumen}

Con el desarrollo de los instrumentos técnicos de visualización en el siglo XX, la mirada se transformó de sujeto en objeto de la representación. La infinitud de imágenes del mundo propiciada por el cine y la fotografía, desde sus comienzos hasta el desarrollo digital, convierte a los dispositivos técnicos en reproductores y productores de mundos. La reflexión sobre esta doble capacidad imitativa y creativa de la técnica ha exigido a la mirada artística volverse sobre sí misma y sobre los dispositivos que la hacen posible, y en los que el ojo se confunde con el objetivo y el hombre con la máquina. Este trabajo quiere señalar algunas variaciones sobre el tema recurrente de la representación de los dispositivos que hacen posible la propia representación: desde la promesa, encarnada por el cine de Vertov, de una mirada infinita, al servicio de una autoconciencia plena, a la amenaza, diseccionada por el ensayismo fílmico de Farocki, de una mirada totalitaria al servicio de instrumentos de vigilancia y control tecnológico de los hombres.

\begin{abstract}
With the development of the technical tools of visualization in the 20th century, the gaze was transformed from subject to object of representation. The infinity of images of the world fostered by cinema and photography, from its beginnings to its digital developments, has transformed technical devices into reproducers and producers of worlds. The reflection on this double, imitative and creative, power of the visual techniques has required the artistic gaze to turn on itself and on the devices that make it possible and in which the eye is confused with the objective and the man with the machine. This paper wants to point out some variations on the recurrent theme of the representation of the devices that make possible the representation itself: from the promise, incarnated by Vertov's cinema, of an infinite gaze at the service of a full self-consciousness, to the threat, dissected by the film essayism of Farocki, of a totalitarian gaze to the service of instruments of surveillance and technological control of men.
\end{abstract}

\section{Palabras clave}

Dispositivo, técnica, filosofía de la imagen, espejos, Benjamin, Heidegger, Vertov, Farocki,

\section{Keywords}

Device, technique, philosophy of images, mirrors, Benjamin, Heidegger, Vertov, Farocki, 


\section{Primera variación. La mirada fija}

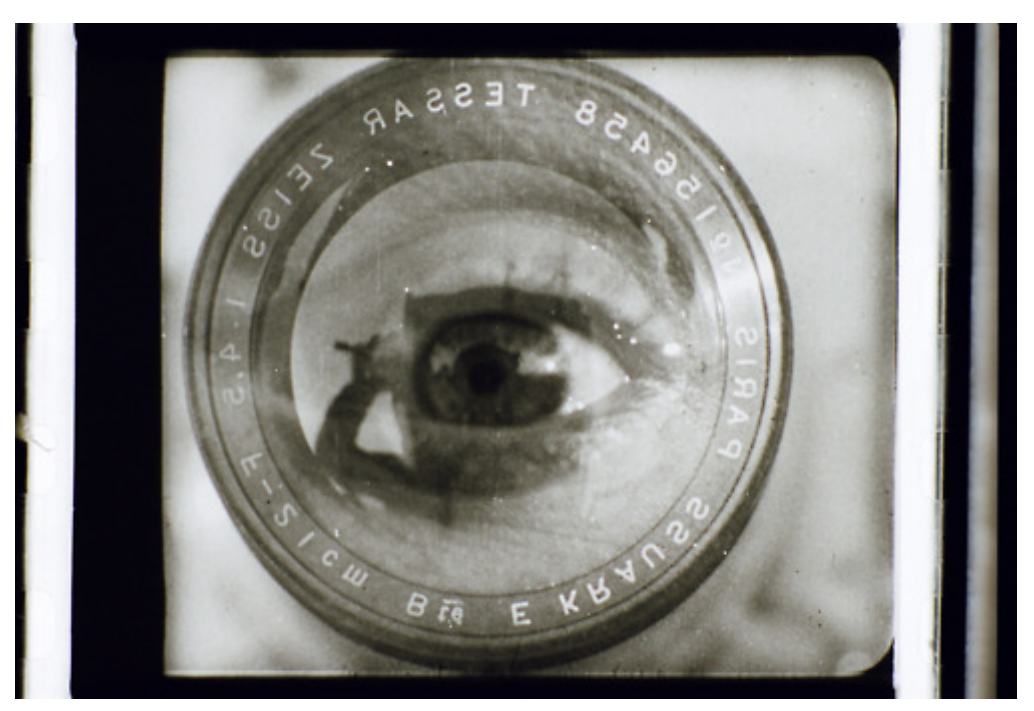

Fotograma de El hombre con la máquina, de Dziga Vertov, 1929

La inquietante mirada fija del fotograma condensa el interminable juego de espejos reflejado por el cine-ojo de Dziga Vertov. En El hombre con la cámara, de 1929, el cineasta ucraniano junto a su hermano, el operador Mikhail Kaufman, llevaban a su extremo la consigna de Rodchenko, en pleno arte del Proletkult, de enseñar a ver los hechos vivos y los objetos cotidianos desde situaciones y ángulos inesperados. Pero, más allá de ese programa pedagógico, cumplían la promesa cinematográfica de una percepción ilimitada de imágenes, que era también la de una percepción inmediata y total de la vida. El desvelamiento de «la vida de repente» era la esencia misma de un «ojo-máquina», que permite «la explicación del mundo visible, aunque sea invisible para el ojo desnudo del hombre». Tras el microscopio y el telescopio, la cámara habría logrado romper la invisibilidad de lo que aguardaba a ser visto ${ }^{1}$. Su verdad poética persigue y prolonga la retórica mecánica y redentora del poeta Maiakovski: «Maiakovski es el cine-ojo. Ve lo que el ojo no ve.» El camino del cine-ojo es el de aquellos para quienes la poesía «gracias a su trabajo / percibirá la masa de los años / y

1 «Nuestro ojo ve muy mal y muy poco, y por ello los hombres concibieron el microscopio para ver los fenómenos invisibles, inventaron el telescopio para ver y explorar los mundos lejanos desconocidos, pusieron a punto la cámara para penetrar más profundamente en el mundo visible, para explorar y registrar los hechos visuales, para no olvidar lo que ocurre y que convendrá tener en cuenta a continuación» (Vertov 2011: 219). 
se hará / pesada / gastada / visible / como ha llegado hasta nosotros / el acueducto / fabricado por los esclavos de Roma.» (Vertov, 2011, 77). Como la poesía, el cine ha de mirar y «ver caminando por las montañas del tiempo a aquel que nadie ve».

La cámara-máquina-ojo, en el movimiento incesante de su mirada fija, encierra la idea de lo sublime propia de un arte que, resuelto a explotar la potencia infinita de la mimesis, rompe con el viejo régimen artístico de la representación y los condicionantes narrativos que subordinaban la imitatio a un principio dramático de ficción. El cine-ojo, en tanto que cine-verdad y cine poético, es también cine documental, enemigo mortal de «los estereotipos de producción», que significativamente oponían muchos más «muros de estupidez» al cineasta que al poeta -como lo confirma el rechazo de la administración soviética a los proyectos cinematográficos de Maiakovski.

La fusión entre ojo y mundo a través de la máquina es la condición para que este cine documental sea un cine de la vida: «No el Cine-ojo por él sino la verdad, gracias a las posibilidades y los medios del Cine-ojo, es decir, personas sin máscaras, sin maquillaje, captarles con el ojo de la cámara en el momento en que no interpretan, leer sus pensamientos desnudados por la cámara» (Vertov, 2011, 201). Cine sin drama, sin fábula y sin actores; un arte depurado de todo tamiz entre el sujeto y el mundo, que produce la verdad en su misma persecución: que identifica la realidad de lo visible con el propio acto de su visión, según el esquema común de su movimiento simultáneo. La esencia de la reproductibilidad de la técnica, del modo como la técnica se produce a sí misma y es representada por el arte, es la movilidad del ojo, que sólo la máquina puede desplegar hasta sus últimas consecuencias. La ontología del montaje desde los comienzos del cine soviético culmina en esta poética cinematográfica que, ajustada al parpadeo de un ojo-máquina, descubre la verdad de las imágenes -de los fotogramas- en la rítmica fuerza de sus intervalos. La imagen vertoviana que simboliza esa suerte de parusía del dinamismo mecánico es, en última instancia, un trampantojo: una cámara humana, un objetivo antropomórfico -un hombre-máquina- cuyas imágenes se suceden con la frenética rapidez de la pupila. El hombre con la cámara resulta un colosal trompe-l'oeil, cuyo ilusionismo se subordina a la fuerza demiúrgica del artista: «Montar y arrancar a la cámara lo que tiene de más característico, de más útil, organizar los fragmentos filmados, arrancados a la vida, en un orden rítmico visual cargado de sentido, en un estrato de yo veo» (Vertov, 2011, 235). 
El cineasta demiurgo reproduce el vértigo del mundo. La esperanza de captar el movimiento mecánico a cuyo ritmo se mueven las masas de automóviles, de artefactos $\mathrm{y}$ de seres humanos, se cumple para Vertov en una poiesis que mimetiza su propio modus operandi. No ha de haber, pues, choque ni trauma sino liberación en el «retorno de lo real» (Foster, 2001), que devuelve la mirada al objetivo y al ojo que lo descubren.

\section{Segunda variación. El espejo móvil.}

En el ensayo La obra de arte en la época de su reproductibilidad técnica, publicado siete años después del estreno en Moscú de la película de Vertov, Walter Benjamin apreciaba en la actitud del actor ante la cámara que lo filma un extrañamiento «de la misma índole que el que siente el hombre ante su aparición en el espejo» ${ }^{2}$ (cf. Benjamin [1936], 1989). La celebración de la movilidad del mundo es desplazada por la angustia de la inestabilidad del sujeto: la sensación de que «ahora esa imagen del espejo puede despegarse de él, se ha hecho transportable». La sutil apreciación nada tiene que ver con una teoría cinematográfica que, como la de El hombre con la cámara, sacrifica la presencia de los actores al ideal de una representación especular pura. Pero es central para analizar los efectos que el énfasis en la conciencia de la representación, propiciada por los dispositivos de la mimesis en la era industrial, tiene sobre el objeto representado y sobre el propio acto de representar.

La evidencia del dispositivo escénico y perceptivo, la muda presencia explícita de la técnica, convierte al sujeto de la mimesis en el reflejo de una mirada sin dueño. Y condena la ilusión cinematográfica al fracaso. «Es imposible»—afirma Benjamin— «ordenar una sola perspectiva sin que todo un mecanismo interfiera en el campo visual del espectador (a no ser que la disposición de su pupila coincida con la de la cámara)». Que Vertov sostuviese su ilusionismo visual mostrando la coincidencia entre pupila y máquina es algo que Benjamin parecía ignorar ${ }^{3}$, aunque sugiriese su hipótesis entre

2 Un extrañamiento, añadamos, semejante al que Jacques Lacan estudiaba en sus lecciones de ese mismo año sobre el "estadio del espejo", donde explicaba las funciones de la imagen especular en la formación infantil de un ego imaginario, construido entre dos fantasías: la que anticipa una plenitud corpórea aún precaria y la que ofrece retroactivamente la imagen amenazante del cuerpo caótico y fragmentario (Lacan, 1963-4).

3 En el citado ensayo Benjamin solo menciona de pasada los Tres cantos a Lenin de Vertov anteriores a El hombre con la cámara-, lo cual es tanto más extraño cuanto que la cámara de cine es un argumento central del texto. 
paréntesis. Para el berlinés, la explicitación del mecanismo hace imposible una mirada inmediata sobre lo real: «en el país de la técnica la visión de la realidad inmediata se ha convertido en una flor imposible». Al identificar esa ausencia de inmediatez con una pérdida de ilusión, estaba atribuyendo los poderes, ilusos o ilusionantes, del cinematógrafo al dispositivo de su mecanismo oculto, encarnado en el montaje. Vertov también suscribiría esa atribución, pero en su cine-ojo no hay mecanismo oculto, como no hay realidad que escape a la mirada. Por eso insiste en exhibir las operaciones del montador: bien congelando de repente un fotograma, bien mostrando el corte de la cinta a manos de la montadora, Elizabeta Svilova, su esposa. No hay mayor prueba de la capacidad del cine ojo para representar la vida como autopoiesis que el repliegue de la mirada hacia su propio dispositivo: los engranajes, los cortes, las combinaciones de imágenes, pero también su mismo rodaje y sobre todo el espacio de tiempo entre ellas. Los formalistas hablaban por esos mismos años de «desvelamiento del recurso» para repensar los efectos estéticos de argucias literarias, que, mucho antes, habían sido concebidos bajo el concepto romántico de ironía.

Pero quizás el fortalecimiento de la intuición de la vida ausente, justo en la presencia inerte del fotograma arrancado del metraje en la mesa del laboratorio, pueda entenderse mejor evocando la barroca Stilleben: una naturaleza muerta donde la vida se hace tanto más presente, cuanto más ausente. La mirada fija al dispositivo, mostrando las imágenes congeladas, sin alma, como un esqueleto extraído del cuerpo fílmico, presiente la eclosión de una vida inagotable. Salvo el osteólogo, nadie mira directamente un esqueleto sin advertir la huella de su pretérita animación o, lo que es lo mismo, sin presentir su movimiento inminente. El cineasta, lejos de parecerse a un fisiólogo, se asemeja más, como advirtió Benjamin, a un cirujano.

En su ensayo, el crítico redirigió la percepción visual hacia el tacto para explorar las modificaciones del aparato perceptivo ante determinados objetos de la mirada. De este modo describió el choque óptico provocado por el cine —análogo al provocado por la visión de la multitud - en los términos de una recepción táctil, antes que visual, simétrica en muchos de sus momentos a las operaciones del «hombre con la cámara». Benjamin describe la oposición entre tales operaciones y las del pintor, sirviéndose de la distinción entre las técnicas del cirujano y el curandero. En buena medida, se trataría de una cuestión de distancias. El pintor — como el curandero que posa superficialmente sus 
manos en la piel— guarda, de hombre a hombre, la distancia con el cuerpo retratado o el cuerpo del paciente-, necesaria para posar sobre él su mirada. En cambio, el hombre con su cámara «se adentra en la textura de los datos» — como el hombre con bisturí se introduce en el cuerpo del paciente-, no para obtener una imagen completa, sino para capturar una imagen fragmentaria, troceada, que pueda recomponerse según diferentes principios.

A pesar de que algunos de sus argumentos sean intercambiables, lo que hace irreconciliables esta concepción táctil de la imagen cinematográfica y el principio de visibilidad total del cine-ojo es el papel que otorgan a la conciencia e inconsciencia en el acto de la percepción. Para los militantes del cine-ojo y, en general, del cine entendido como montaje, el objetivo es elevar la conciencia del espectador de manera que la imagen surta el efecto de «luchar contra las sugestiones mágicas de cualquier clase» (Vertov, 2011, 218). La aspiración a una mimesis total resulta, entonces, inseparable de una pedagógica voluntad de desengaño. La cámara debe servir «para el desciframiento comunista del mundo real» —-proclamaba un Vertov que, sin embargo, apenas fue entendido por los administradores soviéticos del arte. Desengaño y desciframiento — viejos ideales de la cultura visual del Barroco- son los atributos de una visualidad de las imágenes que ha de mover la «conciencia de clase de las personas sanas, que ven y oyen», frente a la inconsciente seducción de la ficción, el drama o los personajes. «Necesitamos hombres conscientes»-proclama Vertov- «y no una masa inconsciente que ceda a la primera sugestión que le llegue». Para Benjamin, por el contrario, la mirada moderna se instala en lo inconsciente: un inconsciente óptico paralelo al pulsional del psicoanálisis.

Las claves de esta óptica se encuentran en el ensayo Sobre algunos temas en Baudelaire ([1939] 1993, 121-179), que Benjamin termina en 1939, tres años después de La obra de arte. Los límites y las aspiraciones de la mirada hacia la multitud que allí se ensayan, conciernen a experiencias muy próximas al efecto de choque del cine. El interés por la imbricación entre la realidad y los dispositivos que la representan es inseparable de la fascinación ejercida por la percepción de la multitud urbana, o más exactamente, por las modificaciones que el aparato perceptivo y motor sufre ante esa multitud y el incesante tráfico humano de la ciudad. El argumento de la inconsciencia y el choque se sostenían en este ensayo sobre las tesis del shock desarrolladas por Freud 
en Más allá del principio de placer y recogidas más tarde por la imagen-trauma de Lacan. Definitivamente, la experiencia no perdura gracias a la conciencia; antes bien, ésta no hace más que neutralizarla al proteger al sujeto de lo que el psicoanalista consideraba energías incontrolables de los estímulos. Dicho de otra manera, el shock, el trauma, irrumpe y se cuela entre los mismos esfuerzos que hace la conciencia por evitarlos. Cuando esa irrupción es interpretada en términos de vivencia, no deja huella ni modificación alguna y se vuelve poéticamente estéril. Escurridiza a toda interpretación, la percepción inmediata, táctil, de la realidad desplaza a la contemplación visual. Como argumentaba Benjamin en el ensayo de 1936, no es el ojo abierto y en constante movimiento lo que puede guiar «las nuevas tareas de la apercepción», sino la «costumbre»: el proceso mediante el que el espectador reconcilia su cuerpo con su confusa mirada sobre la multitud de imágenes, de máquinas y transeúntes.

Pero en el texto sobre Baudelaire, las claves freudianas de esta percepción inconsciente no las ofrece el cine sino la literatura: la tópica del movimiento, que la cámara lleva a su paroxismo, tiene su origen en las respuestas literarias a la amenaza del shock, que se sintetizan en dos modelos: la poesía de Baudelaire, para quien «la vivencia del shock se ha convertido en norma», y la novela de Proust, que ha encontrado las estrategias narrativas de la memoria en el universo de la multitud. El autor de Les Fleurs du mal acoge esa descarga de realidad que desborda la propia percepción a través de sus vivencias traumáticas; pero emancipa tales vivencias de su misma conciencia: la subjetividad es ante todo movimiento («movimientos líricos del alma», «ondulaciones del ensueño», «sobresaltos de la consciencia»), que pide ser representado a través del movimiento de los versos o, mejor aún, de una forma libre de toda fijación: «una prosa poética, musical, sin ritmo y sin rima, suficientemente ágil y lo bastante bronca...» ${ }^{4}$. Ese «ideal obsesivo» de representación «nace sobre todo de la frecuentación de ciudades enormes, del cruce de sus innumerables relaciones», confiesa el propio poeta para regocijo del crítico. «La masa -dice Benjamin- es tan intrínseca en Baudelaire que en vano buscamos en él su descripción».

Esa mirada del flâneur, que persigue el movimiento de la vida urbana concentrado en un instante permanente, no es muy diferente de la que mantiene el ojo inquieto e

4 Tal deseo está expuesto en su dedicatoria del Spleen de Paris (Benjamin [1939] 1993: 134). 
inquietante de la cámara ${ }^{5}$. Ambas son arrebatadas por una seducción semejante. Pero los objetos del deseo son distintos. Uno puede ser, como en el Baudelaire de Benjamin, la passante, que emerge unos segundos entre una indiferenciada multitud. Otro es el deseo físico hacia la fábrica de Dzerjinski que los operadores del cine-ojo, encerrados en su interior, han filmado en condiciones casi inhumanas, pero a la que Vertov no puede ocultar su amor: «No me atrevo a utilizar la palabra enamorado para hablar de mis relaciones con esta fábrica. Pero siento verdaderos deseos de abrazarla y de acariciar sus tubos gigantescos y sus gasómetros negros...» (Vertov, 2011, 60). Proyectado a las calles, ese deseo hacia la máquina se extiende a los movimientos mecánicos de los hombres y las cosas, representados por sacudidas del ojo transparentado en el objetivo. La seducción, en cambio, que Benjamin observa en su lectura de Les fleurs du mal o del Spleen se aproxima más a «la confusión sexual que sobreviene al solitario» y ese «arrobo del hombre de la capital», ese «amor a última vista» hacia la mujer transeúnte, cuyo efímero encuentro «es una despedida para siempre que en el poema coincide con el instante de la seducción» (Benjamin [1939] 1993, 140). Frente a este shock que se incorpora en la continuidad de la vida está ese otro de los movimientos mecánicos, compulsivos, «iguales a golpes de batería», que Baudelaire-Benjamin aprecian en la ordenación de la multitud por los semáforos. Justo en el contexto especial de sometimiento del sensorio humano por la técnica, el cine viene a satisfacer la aspiración a convertir el shock en un principio formal, de modo que la misma rapidez incesante que determina la producción determine también la recepción.

En el ensayo sobre la reproductibilidad, la técnica prometía una ilimitada extensión o proletarización de la obra de arte, al precio de atrofiar su «aura», esa «manifestación irrepetible de una lejanía». Desde la experiencia del poeta que mira la multitud entre la que flota, o la del actor que mira a la cámara que le filma, esa lejanía se convierte en ausencia: «se miraba dentro del aparato (y además detenidamente), ya que el aparato tomaba la imagen del hombre, y no le era a éste devuelta su mirada» (Benjamin [1939], 1993, 163). Es el modelo opuesto al de la pirámide clásica de la pintura desde cuyo vértice externo el espectador siempre podía esperar del otro lado —

5 En su diario de 1926 escribía Vertov: "Hemos abandonado el estudio para ir hacia la vida, hacia el torbellino de los hechos visibles que se atropellan, allí donde está todo el presente, allí donde la gente, los tranvías, las motocicletas y los trenes se encuentran y se separan, donde cada autobús prosigue su itinerario, donde los automóviles van y vienen” (Vertov 2011: 58). 
del punto a donde huyen las líneas perceptivas - la devolución de su propio deseo en una escena que no termina nunca de saciarlo. Dirigida hacia la máquina, «la expectativa que acosa a la mirada del hombre cae en el vacío». El destino de esa mirada, podemos interpretar, no es otro que su disolución dentro del aparato. El cameraman de Vertov no podría estar de acuerdo con este destino. Pero hay otras formas de esperar de la mirada a la máquina una oportunidad para la redención.

\section{Tercera variación. La mirada redentora}

«Mirada hacia lo que es», Einblick in das, was ist, es el título del ciclo de conferencias que Martin Heidegger impartió en 1949, diez años después del texto benjaminiano sobre Baudelaire. En una de ellas, Das Gestell, fijó la concepción metafísica de la técnica que en 1953 reformularía en otra conferencia, La pregunta por la técnica. El término Gestell, «dispositivo», (cf. Heidegger [1953], 1994, 9-37) ${ }^{6}$, puede entenderse, en una primera lectura, como la denominación ontológica de la máquina, el tinglado, el aparato, o, más bien, el conjunto de aparatos que constituyen la técnica. Pronto fue adoptado para describir artilugios como la cámara fotográfica y cinematográfica. Pero Heidegger, siempre empeñado en preservar la esencia de la terminología, aunque fuera a costa de su significado, advierte contra el «uso espantoso de la palabra que ahora se nos impone». Para el filósofo, limitarse a nombrar con ella los instrumentos contribuía a reducir el pensamiento sobre la técnica a mera antropología. No habría que definir el concepto como si se tratara de una clase que agrupa objetos y operaciones que comparten una misma esencia. Su quidditas, en todo caso, no debería remitir a una definición general ni a un género común. En la metafísica heideggeriana el dispositivo es el destino mismo de la máquina: el «modo de hacer salir lo oculto». En este sentido es también un límite. La técnica aquí se ha desubjetivizado hasta comparecer ella misma, ya no como un ente que pueda conceptualizarse, tampoco como un medio de producción, sino ante todo como un límite: el de nuestro pensamiento sobre la técnica, y sobre la relación entre el sujeto y el mundo. «La técnica

6 Utilizamos la traducción de Eustaquio Barjau. Sin embargo, siguiendo a Pedro Cerezo y a otros, cambiamos la traducción que propone Barjau de Gestell como «estructura de emplazamiento» por la más extendida, y por otra parte bastante adecuada al original, de «dispositivo». No utilizamos la expresión escindida «dis-positivo», como sí hace Cerezo, pues no nos parece que la separación silábica, tan cara a los exegetas del maestro, sea relevante para la comprensión del concepto. 
es el destino de nuestra época, donde destino significa lo inesquivable de un proceso que no se puede cambiar.» Todos los procesos de producción material, de acción y de representación artística forman parte de esa estructura de la técnica, que se sustrae a la representación. Se sustrae a ella porque en la técnica, bajo el imperio del dispositivo, no cabe ya distinción entre el sujeto y el objeto. Al desplazar cualquier otro principio de esencia, el universo de la técnica, condensado en el concepto de Gestell, se vuelve ciertamente un peligro. Y, como le gustaba recordar al filósofo parafraseando a su poeta de cabecera: «Miramos al peligro y descubrimos con la mirada el crecimiento de lo que salva». Lo que salva, de nuevo, es la mirada: «Si dirigimos la mirada a la esencia ambigua de la técnica, avistaremos la constelación, el curso estelar del misterio.»

La mirada, como todo lo que salva, tiene que ser «superior al peligro», al dispositivo, pero al mismo tiempo «tiene que estar emparentado con él». En eso consiste su poder: en volvernos al interior de la cámara, del artefacto, y cancelar la distancia entre lo que representa y lo representado. Se trata de comprender con la mirada del poeta —no del cineasta ni del pintor- el fondo último de aquello que amenaza furiosamente al ser. Comprender, en fin, cómo la técnica —ella misma producto humano- ha disuelto, por fin, el humanismo de la tradición europea fustigado por el filósofo. Lo que, en el fondo, persigue esa mirada metafísica hacia «la esencia ambigua de la técnica», es el final de la mirada visual, su salida de sí, su devaluación, su entrega al «curso estelar del misterio». Una ceguera óptica a la medida de la vuelta hacia lo original-duradero-otorgador que por fin reinará salvador entre los hombres...

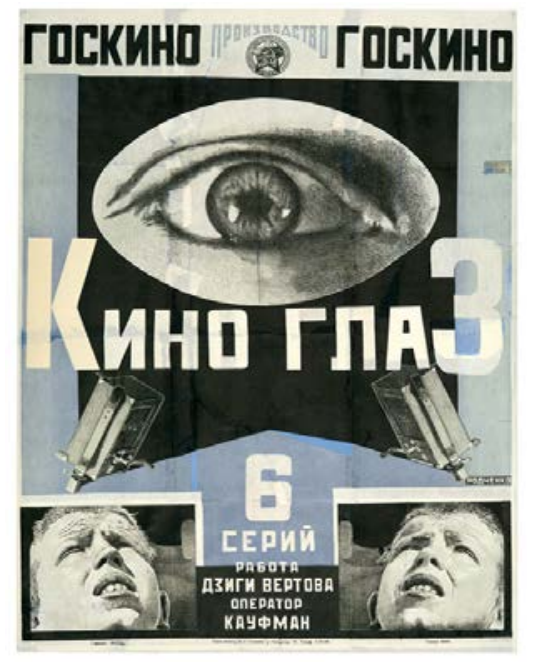

Cartel publicitario de Alexander Roschenko para la producción Cine-Ojo de Dziga Vertov, 1924 
De manera muy diferente, pero con una fascinación no menor por el dispositivo, la redención del cine-ojo apuntaba a la superación del humanismo burgués desde un superhumanismo en el que la humanización de la técnica se identificaba con la tecnificación de lo humano. El cartel que en 1924 dibujó Rodchenko para publicitar la producción de Vertov confiere a la fijación de la mirada móvil un gesto épico, mítico, acentuado quizás por el símbolo del PCUS que lo corona y los dos rostros infantiles idénticos que, desde abajo, elevan sus ojos deslumbrados, como si miraran al sol, hacia las cámaras que parecen filmarles. El nuevo cine se presenta como heraldo de un nuevo hombre:

Soy el cine ojo. Soy un constructor. Te he situado, a ti que te acabo de crear, en una habitación extraordinaria que no existía hasta ahora y que también he creado... Yo, Cine-ojo, creo un hombre mucho más perfecto que el que creó Adán, creo millares de hombres diferentes a partir de diferentes esquemas y dibujos previos. Soy el Cine-ojo. Cojo los brazos de uno, los más fuertes y más hábiles, cojo las piernas de otro, las mejor hechas y más veloces, la cabeza de un tercero, la más bella y expresiva, y, mediante el montaje, creo un hombre nuevo, un hombre perfecto... Soy el cine-ojo. Soy el ojo mecánico. Yo, máquina, muestro el mundo como sólo yo puedo hacerlo (Vertov, 179)

Que la máquina cinematográfica pueda elevar la mirada del hombre-niño-trabajador hacia una vida auténtica, desvelada y nunca más invisible por los límites del cuerpo o los enmascaramientos de la ficción burguesa, es inseparable de la confianza en las virtudes revolucionarias de la técnica moderna. Mientras la mirada de Heidegger al dispositivo sublima su desazón ante una técnica que transforma el Rin de Hölderlin en el Rin de la central energética — el dócil suministrador de la presión hidráulica que hace girar sus turbinas - la mirada de Vertov advierte eufórica que «Lenin es una central eléctrica sobre el Dniéper». La euforia estético política de su cine hacia el hombremáquina es inseparable de la atracción entre el ojo y la cámara y de esa disposición erótica hacia el dispositivo, tanto más evidente cuanto mayores son sus capacidades para transformar el mundo a partir de una revolución esencialmente óptica. Recordemos el enamoramiento del cineasta y su operador hacia la fábrica objeto de su filmación, cuyos tubos y gasómetros desean acariciar. El amor a la técnica, como el amor a la producción, es una expresión revolucionaria de amor al ser humano. En sus diarios Vertov cita los versos El poeta es un obrero de Maiakovski para ilustrarlo: 
Yo mismo soy una fábrica. /Y si bien me faltan chimeneas, /esto quiere decir /que más coraje me cuesta serlo. / ¿Pero quién /se atrevería a llamarnos holgazanes? /Nosotros bruñimos las/mentes con áspera lengua. / ¿Quién es más aquí? / ¿El poeta o el técnico /que procura a los/hombres/tantas ventajas prácticas? /Los dos. /Los corazones son también motores. /El alma/es también fuerza motriz. /Somos iguales.

\section{Cuarta variación. Eye/Machine o la bomba inteligente.}

En los años sesenta del siglo xx, Jean-Luc Godard y Jean Gorin proyectaron un arte cinematográfico entregado a interrumpir, invertir y desbordar los usos de la mirada cinematográfica del capitalismo burgués con el fin de poner ante los ojos lo que éste vuelve invisible. El nombre que bautizó este proyecto, donde la cámara y el montaje son antes que nada instrumentos de revolución o, al menos, de resistencia, fue el de Grupo Dziga Vertov. Tras su disolución, Godard siguió y sigue haciendo un cine que persigue el sentido último de las imágenes representando su envés, redescubriendo las potencias ocultas de su montaje desde su propio desmontaje. Y mostrando reiteradamente cómo, con el apoyo en la banda sonora de una voz literaria, oracular y pedagógica, el cine construye mundo y hace historia(s), integrando lo heterogéneo en una sublimada fraternidad de metáforas e imágenes (Rancière, 2011, 72). En esta explosiva complexio oppositorum de la forma fílmica, la mirada operatoria de Godard al interior del cine clásico convencional, cuyas imágenes descompone y recompone en obras como Histoire(s) du cinema, guarda secretas afinidades electivas con la mirada «clareadora» de Heidegger, que escudriña hasta ponerlo del revés el misterioso dispositivo que le amenaza.

A principios de este siglo, mucho después de disolverse el Grupo Vertov, el cineasta ensayista alemán Harun Farocki presentó una instalación de video titulada Eye/Machine que exploraba la estructura del desbordamiento óptico provocado por la apropiación tecnológica de la mirada. Ahora la unión entre el ojo humano y el ojo de la máquina ha desembocado en la sustitución de aquél por éste, bajo las formas de un inacabable proceso de simulación. Esencia de la precisión visual, la simulación por procesamiento de las imágenes se convierte en el objetivo último de una percepción que aspira a confundir la realidad con su representación. Lo crucial del fenómeno para 
Farocki es que esta transformación haya sido operada por la industria militar cuyos avances han alentado el desarrollo moderno de la producción tecnológica. Dos décadas antes ya ensayó esta tesis en el documental Como se ve (Wie man sieht, 1986) donde los telares, los sistemas de cálculo o la fabricación de motores comparecen indisociables a la construcción de la ametralladora, los tanques y la producción mecánica de la guerra. La película intercalaba imágenes de los revestimientos, las envolturas nobles con las que se disfrazan ya desde hace tiempo los dispositivos fabriles e industriales, poco agradables al gusto burgués: siderurgias con fachadas palaciegas, supermercados con hechuras de museo, motores recubiertos por pulidas superficies deslumbrantes. La mirada al dispositivo se tamiza con mediaciones simuladas, mientras la tecnología, lejos de alimentar el movimiento que entusiasmaba a Vertov, sirve a su ocultamiento, cuando no paralización, en las nuevas guerras, o no tan nuevas, como la de las trincheras de 1914, donde eran las ametralladoras las que se movían mientras los soldados se agazapaban inmóviles o caían, casi sin avanzar, bajo el martilleo de las balas. La mecanización de la mirada se extiende también al deseo sexual por cuerpos exhibidos en imágenes cuyos dispositivos escénicos son los mismos que exhiben los mecanismos militares o civiles: dibujos de mujeres desnudas en la chapa de los bombarderos, gemidos mecánicamente ajustados al montaje de las películas porno durante las sesiones de doblaje, etc. Casi veinte años después, en sus instalaciones sobre el ojo y la máquina realizadas en los primeros años del siglo XXI, Farocki describe minuciosamente cómo la cámara-ojo instalada en la cabeza de los proyectiles simula la percepción de una inteligencia operatoria. Bomba inteligente: las imágenes vertiginosas de la cámara kamikaze proyectadas en la pantalla hasta el fundido final de la explosión fingen la presencia de una subjetividad y, por tanto, de una inteligencia, en el interior del misil que filma la destrucción al mismo tiempo que la produce. Del ideal vertoviano de un cine-ojo que produce mundos al ideal tecnológico de un misil-ojo que destruye objetivos se tiende un arco de tensiones ópticas y táctiles entre el hombre y la máquina, que termina por romperse, según constata Farocki, en favor de «ojos-cámara que recogen imágenes que ya no están pensadas para ser vistas a la escala de ojos humanos, sino para ser reconocidas, a ciegas, por unos parámetros que la máquina ejecuta con precisión» (MACBA, 2001). En la industria como en la guerra, el trabajo del ojo ha sido sustituido por complejas simulaciones que, en efecto, revelan lo invisible, pero no a los ojos de un sujeto humano, como soñaba Vertov, sino a los de dispositivos artificiales, 
ideados para controlar y vigilar el trabajo, el movimiento y hasta el pensamiento de los hombres. Cómo mirar entonces tales dispositivos, cómo representarlos críticamente, cómo medir la distancia exacta que exige su análisis y desmontaje desde una escala estrictamente humana. Tales cuestiones constituyen el objeto de un ensayismo visual que, como el de Farocki, se escribe en la articulación entre el documental y la instalación; en la reflexión y el choque entre imágenes virtuales y reales. Y que busca en su representación fuera del cine, en el museo, en el espacio arquitectónico de la exhibición pública, resquicios descontrolados por donde mirar la amenaza que se oculta bajo las imágenes asépticas de la guerra mecánica y discernir, en fin, entre las víctimas reales y las del videojuego.

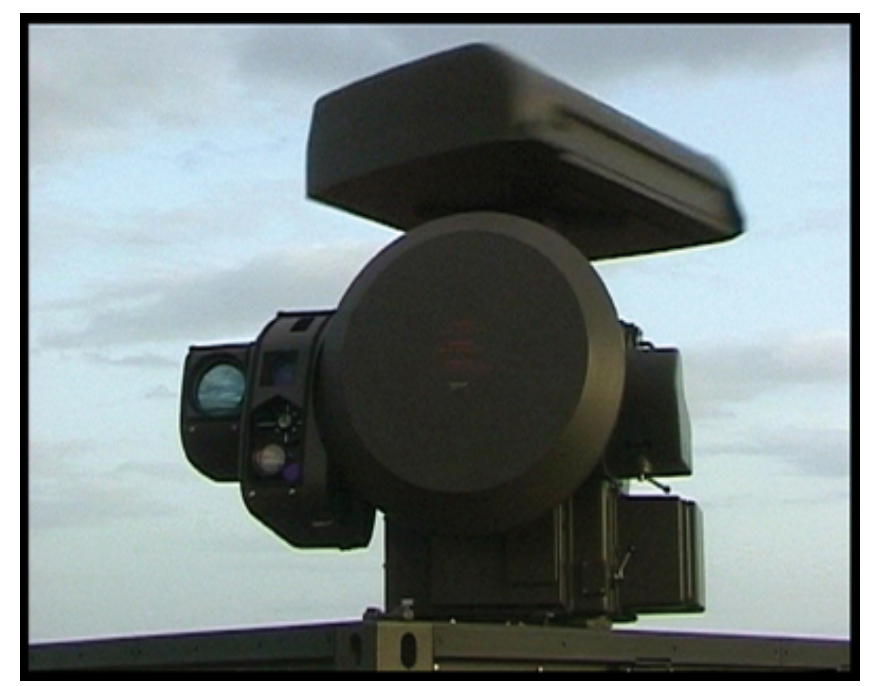

Imagen de la exposición Eye/Machine de Harun Farocki, 2001. 
BIBLIOGRAFÍA

BENJAMIN, W. ([1936] 1989). “La obra de arte en la época de su reproductibilidad técnica”, en Discursos interrumpidos I, Buenos Aires, Taurus, pp. 15-57. Traducción de J. Aguirre.

Benjamin, W. ([1939] 1993). “Sobre algunos temas en Baudelaire”, en Poesía y capitalismo. Iluminaciones II, Madrid, Taurus, pp. 121-170. Traducción de J. Aguirre.

FARocki, H. (2013), Desconfiar de las imágenes, Buenos Aires, Caja Negra Editora. Traducción de J. Giser y A. Marchi

FOSTER, H. (2001). El retorno de lo real. La vanguardia a finales de siglo, Madrid, Akal.

HeideggeR, M. ([1953] 1994). "La pregunta por la técnica”, en Conferencias y artículos, Barcelona, Ediciones del Serbal, pp. 9-37. Traducción de Eustaquio Barjau.

LACAN, J. (1963-64). Les quatre concepts fondamentaux de la psychanalyse. Le Seminaire, XI, Paris, Seuil.

MACBA, http://www.macba.cat/es/eye-machine-i-2469/

RANCIÈRE, J. ([2003] 2011). El destino de las imágenes, Madrid, Politopías.

VerTOV, D. (2011). Memorias de un cineasta bolchevique, Madrid, Capitán Swing. Traducción de J. Jordá. 